\title{
Use of technology in improving urban transport
}

\author{
DOI: https://doi.org/10.7307/ptsm.2020.9
}

Iva Toš $\check{s}^{1}$

City of Zagreb, ${ }^{1}$

\section{Keywords:}

Smart city

Smart solution

Technology

Urban

development

\begin{abstract}
People must be able to move around to meet their basic needs, but also additional needs that include rest and recreation. The growing trend of urbanization leads to population growth in cities, and thus to an increase in demands on the transport system in cities, with the achievement of sustainable urban mobility as one of the key challenges. Cities worldwide have started to look for solutions which enable transportation linkages, mixed land uses and high-quality services with long - term positive effect on the economy. Today cities are flooded with a range of data, both useful and useless. In that large database, city administration should recognize the importance of processing, analyzing and mathematical-statistical processing. Each city should determine its vision, goals and strategies of transforming itself and developing smart services at basis of collected data and their processing. Future initiatives of a smart city and smart transportation should be focused on creating efficient, environmentally friendly transport, based on interactive solutions for smartphones. There are a lot of applications and technologies that contribute to smart cities. Although technology is evolving every day, there is always room for improvement by using available data, smart management and individual approach to each city, it is possible to achieve an improvement in public transport services, which would also improve the quality of life in urban areas.
\end{abstract}

\section{Introduction}

The growing trend of urbanization leads to population growth in cities, and thus to an increase in demands on the transport system in cities, with the achievement of sustainable urban mobility as one of the key challenges. Existing mobility systems cannot respond to the increased demand for transport. Cities have so far mostly addressed these challenges in the traditional way, almost exclusively by increasing capacity, but such an approach is neither effective nor sustainable in the long run. With growing demand, mobility requirements are changing and evolving, and users' needs for unlimited and efficient movement are growing. A holistic approach to urban mobility is needed so it can optimize supply and demand solutions in order to implement the most sustainable solutions possible. It also requires a shift from a reactive approach to urban mobility to a more proactive model that anticipates future changes and trends and takes advantage of new solutions. New ways of managing urban mobility, innovative financing, regulatory support and citizen involvement must be drivers of change.

\section{Definition of Smart city}

Cities play prime role in social and economic aspect worldwide and have huge impact on the environment. As a result, nowadays most resources are consumed in cities, contributing to their economic importance, but also to their poor environmental performance. The current scenario requires finding ways to manage new challenges. Cities worldwide have started to look for solutions which enable transportation linkages, mixed land uses and high-quality services with long - term positive effect on the economy. For instance, high quality and more efficient public transport that responds to economic needs and connects labor with employment is considered a key element for city growth. Many of the new approaches related to urban services have been based on harnessing technologies, helping to create smart cities. [1] 
Mobility is a function of individuals, communities and economic activities. People must be able to move around to meet their basic needs, but also additional needs that include rest and recreation. In cities, high quality mobility is necessary for the successful functioning of various sectors and the creation of new jobs, and it also plays a key role in creating an attractive environment for citizens and the business community. At the same time, effective mobility is one of the main challenges facing cities in terms of increased demands, often in the context of existing (inadequate) infrastructure, while increasing citizens' awareness of newly available technologies that are more environmentally friendly and efficient. [2]

The fact that cities are becoming drivers of development, regional, national and international economic centers and centers of social development, it is further complicating the mobility context. The combined impact of population growth, demographic change and urbanization increases the need to travel to urban centers, suburbs and between them. As the need for mobility grows, so does the awareness and fear of increasing levels of greenhouse gas emissions and noise, as well as air pollution, to which traffic contributes significantly. [2]

The smart mobility system requires the availability of infrastructure, including physical infrastructure, communication and information infrastructure, IoT platform, application level etc. Without the proper representation of all components of this system, smart mobility solutions cannot fulfill their full potential to manage operational efficiency and user demand. Coordination and integration between the various components in the structure is extremely important. [2]

Smart cities must offer effective intelligent mobility solutions while supporting innovation, promoting a cooperative ecosystem and achieving sustainability goals. These challenges are part of the rapidly changing landscape of urban mobility as seen through the perspective of a smart city planner. Strategies for addressing the challenges of urban mobility and solving the problems of urban mobility are specific from city to city and include [7]:

- Developing effective, balanced, safe and secure public transport systems, including Mobility-as-aService (MaaS) and other platforms,

- Adaptation to the innovation and acceptance of vehicles (autonomous, connected, electric, communal, station-less),

- Develop guidelines and strategies to promote compliance with air quality standards and other measures to improve the quality of life,

- Development of public-private partnerships (PPPs) and cooperation with knowledge institutes to address issues of air quality, traffic congestion and sustainability,

- Building a sustainable infrastructure - physical and digital - to support innovative mobility solutions from the public and private sectors.

\section{Smart data}

Today cities are flooded with a range of data, both useful and useless. In that large database, city administration should recognize the importance of processing, analysis and mathematical-statistical processing. Growth and development of smart city is based on smart decisions that come from the collecting and processing of smart data. Data needs to be collected systematically and connected with certain city services, transport, traffic, infrastructure, etc. Smart data should enable faster and more rational action in sectors where it is necessary and will prevent waste of resources in parts where the concept of a smart city would not be successful. Each city should determine its vision, goals and strategies of transforming itself and developing smart services at basis of collected data and their processing. What is good and purposeful in one city, is not necessarily good and profitable in another.

Smart data is not just data needed by city administrations. Their clear and transparent opening to the public makes it easier and faster for investing, making economic and private decisions, making everyday life easier to every citizen. Digital availability, special network interfaces, applications, e-government, e-administration - these are all parts of the collection and presenting smart data in smart city. [3]

In fact, smart data makes up the basic interface and infrastructure for creating a smart city. Today digital data processing also enables theirs spatial visualization based on real infrastructural and social flows some city. 
GIS database and GIS smart data processing a simple way allows the visualization of city problems as the city administration so do their inhabitants. The goal of smart data visualization and analysis is facilitate decisions on the growth and development of a city, its potential, his weaknesses and strengths. [3]

From all the above it is clear that today in the era of modern technologies, smart data, smartphones, mobile networks and the Internet there is need for rational, statistically correct data collection, their processing by visualization in order to make decisions based on profession and science, and not based on undefined policy or instinct. [3]

\section{Smart urban transport}

Residents and visitors (guests and tourists) primarily need high and fast mobility. Urban mobility should meet safety standards and be easy to use. Cars, trains, buses, bicycles and motorcycles are basic concept of participation in transport within an urban metropolitan area. Systems of public and private transportation are interconnected and interactive. In that interaction, in the absence of constructive smart solutions, there is an impression of disorganization, and occasionally in some larger cities and chaos in traffic. However, transportation solutions within a city mostly depend on the size of that city. Cities with higher population density traditionally make greater efforts to develop local public transport. On the other hand, the size of the city and the higher population density lead to inefficiency of certain areas such as transport, security or consumption of energy, which makes it less smart, but creates more potential for using technologies in solving problems.

Common public transport problems such as inefficient timetables, wrong stops, dirty vehicles, unforeseen delays, poor Air conditioning, poor maintenance, are part of everyday life. Future initiatives of a smart city and smart transportation should be focused on creation efficient, environmentally friendly transport, based on interactive solutions for smartphones with options such as ticket payment, selecting the fastest line, notification of delays and technical problems etc. One of the biggest problems cities face in the domain of transport, and especially tourist cities, is parking. Great efforts and a significant part of smart solutions cities should focus on controlling and monitoring of parking spaces with effective software and interactive solutions that direct traffic and parking with a goal of reducing traffic jams.

The concept of smart cities in the domain of public and private transport should rely on software and technology solutions that improve the existing infrastructure facilitate management and improve transportation information system and make it interactive. Examples of such solutions can be found in many cities, such as: mobile parking fees, car rental applications, interactive smartphone applications containing an integrated public transport and ticket charging system, smart cameras and sensors to identify free parking spaces, traffic jams, traffic diversions, etc.

Although it can't be said that some city is smart only because of the level of using technology, the future of technology development and its integration into all city systems is actually one of the foundations of how a city becomes smarter. All potentially good, smart and simple solutions start from digital infrastructure and its availability. What a smart city concept should ensure is stable digital infrastructure and simple, fast and inexpensive access to it, in a way that is acceptable to all (population, guests and tourists and companies). The requirement of a smart city concept is that there is a physical networking between all dimensions of the smart city, ie transport, residents, resources, city administration, city public services and the economy, to make simple and easier solutions effective.

\section{Example of smart urban mobility solution}

In today's world there are many applications and technologies that contribute to smart cities and there are some of them [7]: 


\section{Mobility as a Service (MaaS)}

Moovel, an innovative MaaS platform, combines and facilitates the use of multimodal transport and shared mobility services and enables payment via a single interface. This intelligent solution for urban mobility offers a multimodal function that bundles transport options such as public transport, on-demand services, vehicle sharing, bicycle sharing and ride hailing. With access to the Moovel app, customers can book and pay for mobility services via an integrated account.

\section{Sustainable travel behaviour}

Innovactory is committed to make the travel behaviour of its users more sustainable through the development of TimesUpp, an intelligent travel assistant. With more than 150,000 users, TimesUpp transforms a user's calendar into the perfect travel assistant, advising the best time and mode of transport to get to their destination, and providing real-time information about traffic jams and other unexpected delays.

In 2017, Innovactory TimesUpp introduced incentive programs with the aim of reducing transport-related emissions and avoiding more than 250,000 car journeys. This led to a $\mathrm{CO} 2$ saving of almost 650 tons. In 2018, TimesUpp launched the Smart Traveling! Campaign - a SmartwayZ.NL initiative with public and private sector stakeholders - to reward commuters for reducing the use of their car by switching to cycling, public transport, or working from home.

\section{Intelligent Transportation Systems (ITS)}

PSIRoads is an intelligent traffic management solution that offers decision support through artificial intelligence. This intelligent urban mobility solution offers intelligent traffic management services such as traffic light phase changes, traffic user information and dynamic changes in traffic capacity. This mobility solution is designed to help transport authorities achieve strategic goals by minimizing vehicle emissions and reducing traffic congestion in residential areas.

\section{$>$ Traffic congestion reduction services}

An estimated $30 \%$ of traffic congestion in urban areas is caused by finding a parking space. Parquery - a cloudbased smart parking solution that has been implemented in more than 15 cities worldwide - provides parking space managers with precise data on the use of parking spaces and also supports adaptive street light management, intelligent traffic management and retail services for easy navigation in a smart city.

\section{$>$ Micromobility management}

Micromobility - including systems and fleets of shared bicycles and electric (pedal) scooters. The attractiveness of cycling and (pedal) scooters for cities and start-ups is obvious: micro-mobility systems complement each other while they steal trips from other modes of transport".

eCooltra is a European scooter sharing innovator with a fleet of more than 3,000 electric scooters in use in five cities. With the eCooltra app, customers can book and activate a freely available scooter and only pay for the minutes of actual use. This e-mobility solution aims to improve the quality of life for customers, contribute to sustainability in the city and reduce $\mathrm{CO} 2$ emissions.

\section{Innovation in local public transport (ÖPNV)}

An innovative passenger information system was designed and implemented in the Polish city of Lublin. This project included the modernization of the urban transport infrastructure and the city's bus fleet. The project included the installation of GSM and GPRS equipment in the vehicles, electronic displays at bus stops, control center / dispatching software and a website with dynamic information for passengers. Lublin was voted "Smart City of the Year" among cities with a population between 100,000 and 350,000 for its innovations in traffic 
management and transport solutions. By modernizing the transport infrastructure and improving communication with passengers, Lublin shows that medium-sized cities can achieve a far-reaching upgrade in user experience and the quality of urban mobility.

\section{$>$ Reducing mobility poverty}

The HiReach project, a research and innovation measure funded by the EU's Horizon 2020 program, has the mission of finding solutions to improve the accessibility, inclusion and fair design of mobility:

- Research into viable business models for affordable, modular and replicable mobility services (local public transport, ridesharing, minibuses).

- Generation and testing of mobility solutions for start-ups and companies.

- Enabling the viability and scaling of new mobility business models.

\section{$>$ PassageWay}

PassageWay designed Real-time Smart Mobility Information and Digital Wayfinding Signs that can help connect people with their local mobility options. From helping stadiums with crowd dispersal and encouraging shoppers to linger longer, to helping patients or student's access convenient mobility and workplace sustainable travel plans, PassageWay offers a unique solution. Currently it is used in London, United Kingdom. [4]

PassageWay digital signs are delivered as web URLs displaying auto-updating (typically every 8 seconds) fully responsive web pages with the appropriate content. They are suitable for virtually any sized screen, at any orientation. They are optimised for modern browsers, particularly Chrome. PassageWay signs are designed for the public realm, because of this they are deliberately not interactive, to enable the maximum number of people to view the information concurrently. Screens displaying PassageWay signs need to be connected to the Internet, typically with a $3 \mathrm{G}$ or greater connection. If a screen loses Internet connectivity the sign will display an appropriate customer service message prior to automatic restoration once connectivity is resumed. [5]

PassageWay digital signs display real-time data around the availability of local public transport options along with any applicable alerts that may affect the passenger journey. Each PassageWay sign is carefully curated for a specific location (to within a few meters). Working with Transport Authorities and their agencies, it can identify the mobility options to highlight and suggest optimum data selections. [5]

As previously mentioned, PassageWay enables stadiums and event venues to leverage existing digital screens and totems to help visitors exit safely and quickly via public transport. It can also be used in schools, colleges, healthcare centres, workplace, shopping centres etc. It can tell timetable of all transport modes, availability of city bicycle, delays etc. using real time database. 


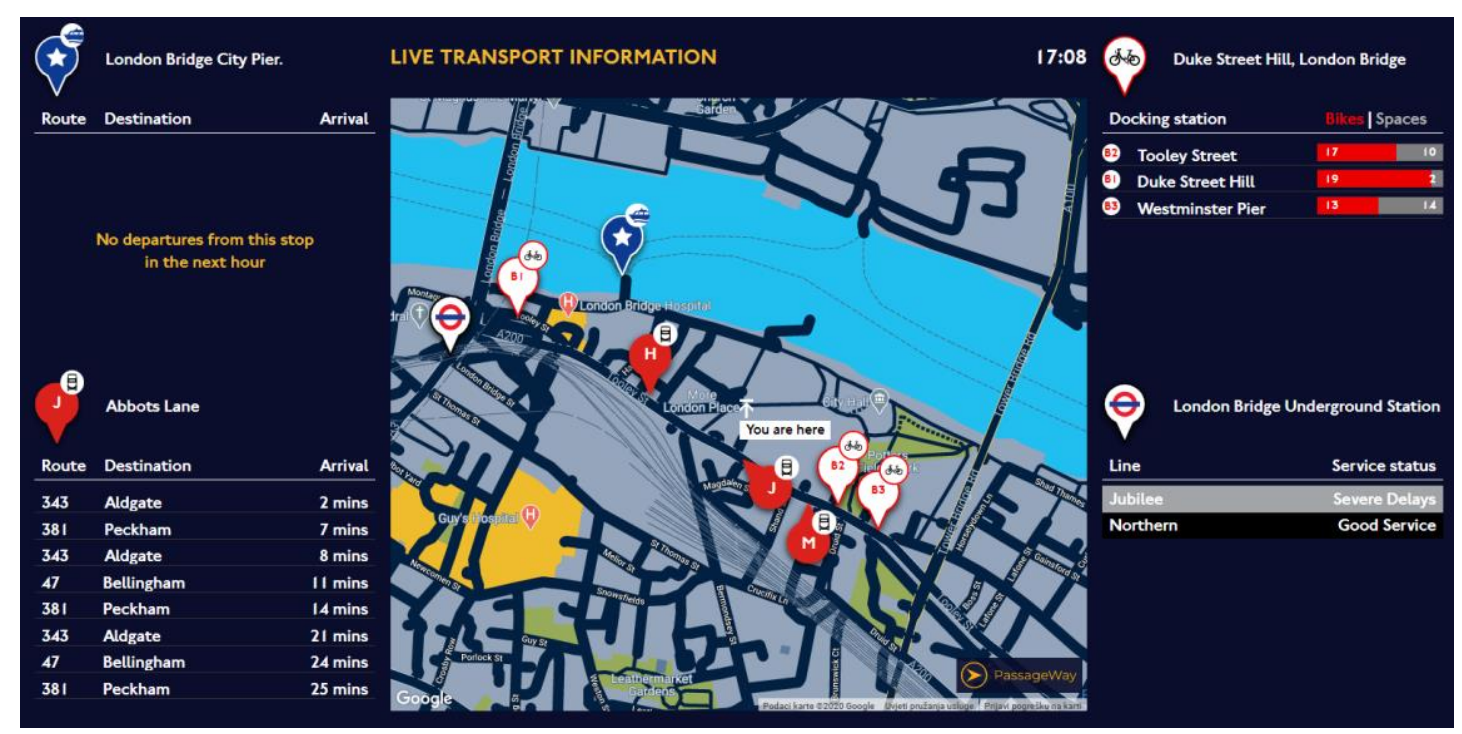

Figure 1. Example of PassageWay sign

Source: [6]

\section{Conclusion}

People must be able to move around to meet their basic needs, but also additional needs that include rest and recreation. The growing trend of urbanization leads to population growth in cities, and thus to an increase in demands on the transport system in cities, with the achievement of sustainable urban mobility as one of the key challenges. Existing mobility systems cannot respond to the increased demand for transport. Cities worldwide have started to look for solutions which enable transportation linkages, mixed land uses and high quality services with long - term positive effect on the economy. Today cities are flooded with a range of data, both useful and useless. In that large database, city administration should recognize the importance of processing, analysis and mathematical-statistical processing. Each city should determine its vision, goals and strategies of transforming itself and developing smart services at basis of collected data and their processing. Future initiatives of a smart city and smart transportation should be focused on creation efficient, environmentally friendly transport, based on interactive solutions for smartphones with options such as ticket payment, selecting the fastest line, notification of delays and technical problems etc. There are a lot of applications and technologies that contribute to smart cities such as Moovel, TimesUpp, PSIRoads, Parquery, PassageWay. Although technology is evolving every day, there is always room for improvement by using available data, smart management and individual approach to each city, it is possible to achieve an improvement in public transport services, which would also improve the quality of life in urban areas.

\section{References}

[1] Albino, V., Berardi, U., Dangelico, R.M. Smart Cities: Definitions, Dimensions, Performance and Initiatives in Urban Technology. Journal of Urban Technology 22 (1). pp. 3-21. 2015.

[2] REGEA. Okvirna strategija Grada Zagreba - Zagreb smart city, vizija do 2030. City of Zagreb. Zagreb. 2018.

[3] Paliaga, M., Oliva, E. Trendovi u primjeni koncepta pametnih gradova. Ekonomska misao i praksa, No. 2. pp. 565-583. 2018.

[4] Bee smart city. Passage way. Available at: https://www.beesmart.city/solutions/passageway [Accessed: October 15, 2020]

[5] PassageWay. Public Transport \& Wayfinding Digital Signs. Available at: https://passageway.com/passenger-information [Accessed: October 01, 2020]

[6] PassageWay. Live Transport Information. Available at: https://signs.passageway.com/sign/39/h0FYhc48KE [Accessed: October 05, 2020] 
Toš, I. / Public Transport \& Smart Mobility 2020, 73-78

[7] Bee smart city. Urban Mobility: Challenges and Solutions in Smart Cities. Available at: https://hub.beesmart.city/de/smart-city-loesungen/urbane-mobilitaet-herausforderungen-undloesungen-in-smart-cities [Accessed: October 10, 2020] 